\title{
Contribuições para Indicação Geográfica (IG): considerações sobre Itororó - BA como uma potencial IG para Carne de Sol
}

\section{Contributions for Geographical Indication (GI): Considerations About Itororó - BA as Potential IG for the Meat of the Sun}

\author{
Joelito da Cruz Santos ${ }^{1}$ \\ Wagna Piler Carvalho dos Santos ${ }^{1}$ \\ ${ }^{1}$ Instituto Federal de Educação Ciência e Tecnologia da Bahia, Salvador, BA, Brasil
}

\begin{abstract}
Resumo
Este trabalho tratou de identificar as características associadas da carne de sol produzida no município de Itororó, Bahia, Brasil, com o objetivo de demonstrar a potencialidade de registro de Indicação Geográfica (IG) para o território abrangido pelo município. A pesquisa foi dividida em duas partes, diferenciação do produto e a determinação de área de indicação geográfica. Feita a revisão bibliográfica, foram comparadas as ações, as características existentes no município em questão, assim como as características em relação ao produto. Conclui-se que há a potencialidade de o território do município de Itororó, BA obter a proteção industrial pela Indicação Geográfica para o produto alimentício "carne do sol".
\end{abstract}

Palavras-chave: Indicação Geográfica. Carne de Sol. Itororó.

\begin{abstract}
This work aimed to identify the associated characteristics of the sun meat produced in the municipality of Itororó, Bahia, Brazil, in order to demonstrate the potential of recording a Geographic Indication (GI) for the territory covered by the municipality. The research was divided into two parts, product differentiation and the determination of geographical indication area. After the bibliographic review, the existing actions and characteristics of the municipality in question were compared, as well as in relation to the product. Thus, the potential of the territory of the municipality of Itororó-BA was obtained in obtaining the industrial protection by the Geographical Indication for the food product "beef of the sun".
\end{abstract}

Keywords: Geographical Indication. Beef of the Sun. Itororó.

Área Tecnológica: Propriedade Intelectual. Inovação.

\section{Introdução}

As Indicações Geográficas (IGs) podem ser definidas como uma categoria de propriedade industrial na qual está envolvido um coletivo organizado da sociedade em prol da oferta de determinado produto ou serviço, com características peculiares a um território. 
A produção de bens e serviços tradicionais é bastante diversificada no Brasil. Dessa forma, com o objetivo de se diferenciar dos seus concorrentes e de caracterizar a origem ou a procedência do produto ou do serviço, existe a possibilidade de os produtores pleitearem a indicação geográfica. Todavia, a tarefa possui certo grau de dificuldade, pois os pretendentes precisam cumprir alguns requisitos previstos na legislação.

Segundo dados publicados pelo Instituto Nacional de Propriedade Industrial (INPI), que constam na Planilha de Acompanhamento dos Pedidos/Registros de Indicações Geográficas, de 30 de janeiro de 2018, atualmente, existem 67 registros de indicação geográfica concedidos, dos quais 18 são Denominação de Origem (DO), 10 desses registros são nacionais e oito estrangeiros. Por outro lado, quanto à espécie, Indicação de Procedência (IP), foram identificados 49 registros (INSTITUTO NACIONAL DE PROPRIEDADE INDUSTRIAL, 2018b).

O propósito deste trabalho é demonstrar os requisitos necessários para se registrar uma Indicação Geográfica (IG), tomando a carne de sol da região de Itororó, BA, Brasil, como um possível caso de IG, considerando a modalidade mais adequada, a Indicação de Procedência (IP) ou a Denominação de Origem (DO), à luz da legislação vigente, e verificando a viabilidade de adequação com o produto e com a região de potencial para possível indicação.

O artigo está organizado de acordo com as seguintes seções: Introdução; Metodologia; Resultados e Discussões, seção que está subdividida em: a IG segundo a norma legal, o município de Itororó-Ba, as considerações sobre o potencial para a IG de Itororó, o produto carne de sol, a análise do potencial do caso Itororó à luz da LPI, os possíveis ganhos com a existência da IG; $e$ as Considerações Finais.

\section{Metodologia}

Para a elaboração deste trabalho foi realizada pesquisa documental e foram analisadas as legislações e as regulamentações, nacional e internacional, pertinentes à matéria Indicação Geográfica.

Além disso, foi realizada uma pesquisa nas bases de dados bibliográficos (Scielo, Scopus, Google Acadêmico), associando os termos "indicação geográfica", "alimento", "carne de sol" em português e em inglês. Foram analisados os artigos técnico-científicos e outras fontes oficiais e governamentais que abordam conceitos relacionados ao produto carne de sol, à delimitação geográfica e à comprovação de notoriedade.

Como o produto em questão avaliado neste estudo, com potencial de proteção com Indicação Geográfica, trata-se de um alimento, também foi consultada e analisada a legislação relativa ao manuseio de alimentos.

\section{Resultados e Discussão}

Nesta seção serão discutidos estes assuntos: a IG segundo a norma legal, o município de Itororó-Ba, as considerações sobre o potencial para a IG de Itororó, o produto carne de sol, a análise do potencial do caso Itororó à luz da LPI, os possíveis ganhos com a existência da IG 


\subsection{A IG Segundo a Normativa Legal}

Segundo Costa (2014, p. 27),

As Indicações Geográficas (IGs) não são práticas contemporâneas. Já existem desde a Antiguidade. Naqueles tempos é como se as indicações geográficas fossem uma espécie de sobrenome de produtos de qualidade reconhecida pelos consumidores da época.

Na contemporaneidade, a Indicação geográfica é definida e normatizada por diversos acordos internacionais: Convenção da União de Paris (1883); Acordo de Madri para a Repressão das Falsas Indicações de Procedência (1891); e Acordo de Lisboa relativo à Proteção das Denominações de Origem (1958). E, mais recentemente, em 1994, pelo Acordo sobre Aspectos dos Direitos de Propriedade Intelectual, relacionados ao Comércio, mais conhecido pela sigla TRIPS (do inglês Agreement on Trade-Related Aspects of Intellectual Property Rights). Nesse caso, a IG é definida como

Indicações que identifiquem um produto como originário do território de um membro, ou região ou localidade deste território, quando suas qualidades, reputação ou outras características sejam essencialmente atribuídas à sua origem geográfica. (TRIPS, 1994, art. 22)

No Brasil, a Lei n. 9.279/96, Lei de Propriedade Industrial (LPI), considerando a perspectiva de se obter a indicação geográfica, determina o preenchimento de requisitos de elementos norteadores; esses elementos estão mais detalhadamente descritos pela Instrução Normativa n. 25/2013 do INPI, que estabelece as condições para o registro das indicações geográficas, citando em seus artigos $1^{\circ}, 2^{\circ}$ e $3^{\circ}$ as condições necessárias:

Artigo $1^{\circ}$ Estabelecer as condições para o registro das Indicações Geográficas no INPI.

Parágrafo único. O registro referido no "caput" é de natureza declaratória e implica no reconhecimento das Indicações Geográficas.

Artigo $2^{\circ}$ Para os fins desta Instrução Normativa, constitui Indicação Geográfica a Indicação de Procedência e a Denominação de Origem.

$\S 1^{\circ}$ Considera-se a Indicação de Procedência o nome geográfico de país,

Cidade, região ou localidade de seu território, que tenha tornado conhecido como centro de extração, produção ou fabricação de determinado produto ou de prestação de determinado serviço.

$\S 2^{\circ}$ Considera-se Denominação de Origem o nome geográfico de país, cidade, região ou localidade de seu território, que designe produto ou serviço cujas qualidades ou características se devam exclusiva ou essencialmente ao meio geográfico, incluídos fatores naturais e humanos.

Artigo $3^{\circ}$ As disposições desta Instrução Normativa aplicam-se, ainda, à representação gráfica ou figurativa da Indicação Geográfica, bem como à representação geográfica de país, cidade, região ou localidade de seu território de cujo nome seja indicação geográfica. (INSTITUTO NACIONAL DE PROPRIEDADE INDUSTRIAL, 2013, art. $1^{\circ}, 2^{\circ}, 3^{\circ}$ )

À luz da Lei de Propriedade Industrial, Maiorki e Dallabrida (2015, p. 14) definem IG como uma qualidade relacionada a fatores humanos e ambientais: 
A Indicação Geográfica (IG) refere-se a uma qualidade atribuída a um produto originário de um território cujas características são inerentes a sua origem geográfica. Representa uma qualidade relacionada ao meio natural ou a fatores humanos, que lhes atribuem notoriedade e especificidade territorial.

Comparando o artigo 22 do TRIPS com a legislação brasileira (Lei n. 9.279/96) pertinente, pode-se perceber que o Acordo não exige que a IG constitua necessariamente um nome geográfico, já que não distingue as espécies de IGs (indicação de procedência e denominação de origem) e exclui os fatores humanos para caracterizar uma IG. Dessa maneira, pode-se afirmar que a doutrina é, ao mesmo tempo, mais detalhista e mais abrangente que a diretriz internacional.

É fundamental, para fins de registro, fazer uma observação sobre a legislação brasileira, com destaque à LPI, e os acordos internacionais com relação à matéria, dos quais o Brasil é signatário importante. Segundo Russo et al. (2016, p. 137):

[...] a legislação é uma aliada para o fortalecimento e garantia de novos registros, com a finalidade de desenvolver localidades que se destacam pela produção de um determinado produto ou serviço, contribuindo econômico e socialmente para região. A estimativa é que cresça cada vez mais registros de IG no Brasil, com uma vistoria severa para que as indicações registradas estejam de acordo com a legislação.

Entretanto, outros elementos podem influenciar de maneira significativa na concessão da indicação geográfica, por se tratar de um alimento tradicional, portanto, não são produzidos industrialmente. Nesse sentido, os alimentos tradicionais são a forma com a qual o produtor gera o alimento com processo diferenciado, criando uma identificação com o local (ZUIN; ZUIN, 2008). Segundo Valente et al. (2012), a IG agrega valor ao produto ou serviço, além de lhe conferir um diferencial competitivo em função das características do local de origem.

Portanto, o registro Indicação geográfica, orientado e originado a partir da criação da Lei n. 9.279, de 14 de maio de 1996, é o conjunto composto de Indicação de Procedência (IP) e de Denominação de Origem (DO).

Para o Instituto Nacional de Propriedade Industrial (INPI), órgão responsável pelo estabelecimento das regras e condições de registro da IG no Brasil,

As Indicações Geográficas (IGs) são ferramentas coletivas de proteção e valorização de produtos ou serviços vinculados a determinados territórios. Elas agregam valor ao produto ou serviço, permitindo estabelecer um diferencial competitivo frente aos concorrentes, além de possibilitar a organização produtiva e a promoção turística e cultural da região (INSTITUTO NACIONAL DE PROPRIEDADE INDUSTRIAL, 2018a, p. 45)

O registro concedido atribui aos produtos ou serviços características baseadas no seu local de origem, e esse registro agrega valor e respeitabilidade no mercado consumidor, além de significar uma identidade própria, sendo facilmente destacado entre os produtos similares ou concorrentes diretos, na mesma fatia de mercado. 


\subsection{O Município de Itororó - BA}

O povoamento do território que abrange o atual município de Itororó na Bahia, ocorreu no final do século XIX por agricultores que se estabeleceram às margens do rio Colônia, assim formou-se o povoado denominado "Garimpo Rico". Em 1994, o nome foi modificado para Itapuí, criado pela Lei Estadual n. 8.800, de 1934, era um distrito subordinado ao município de Itabuna que passou a denominar-se Itororó no início dos anos de 1940. Por meio da Lei Estadual n. 628, de 30 de dezembro de 1953, o distrito de Itororó passou a constituir o novo município de Ibicaraí. Na sequência, Itororó foi emancipado (Lei Estadual n. 1.045, de 22 de agosto de 1958) e, no início da década dos anos 1980, os distritos de Itati e Rio do Meio, ambos ex-povoados, foram anexados aos municípios de Itororó (Lei Estadual n. 4.048, de 14 de maio de 1982) (INSTITUTO BRASILEIRO DE GEOGRAFIA E ESTATÍSTICA, 2016).

Quanto aos dados econômicos, de acordo com as informações do último Censo realizado em 2010, o município de Itororó possui uma população de 19.914 habitantes, com densidade demográfica de 65,5 hab $/ \mathrm{km}^{2}$; segundo Censo de 2015, o município possui PIB per capita de $\mathrm{R} \$ 8.904,52$, o salário médio mensal era de 1,5 salários mínimos, a proporção de pessoas ocupadas em relação à população total era de $11,7 \%$, caso fosse feita uma comparação com os outros municípios do estado, Itororó ocupava a $69^{\circ}$ colocação entre 417 municípios (INSTITUTO BRASILEIRO DE GEOGRAFIA E ESTATÍSTICA, 2016).

O município de Itororó está localizado na mesorregião, Centro Sul Baiano e microrregião Itapetinga, tendo como municípios limítrofes, Itapetinga, Itajú do Colônia, Firmino Alves, Caatiba, Itambé, Nova Canaã e Ibicuí, conforme mostram os dados da Figura 1.

Figura 1 - Mapa político da região que abrange o município de Itororó

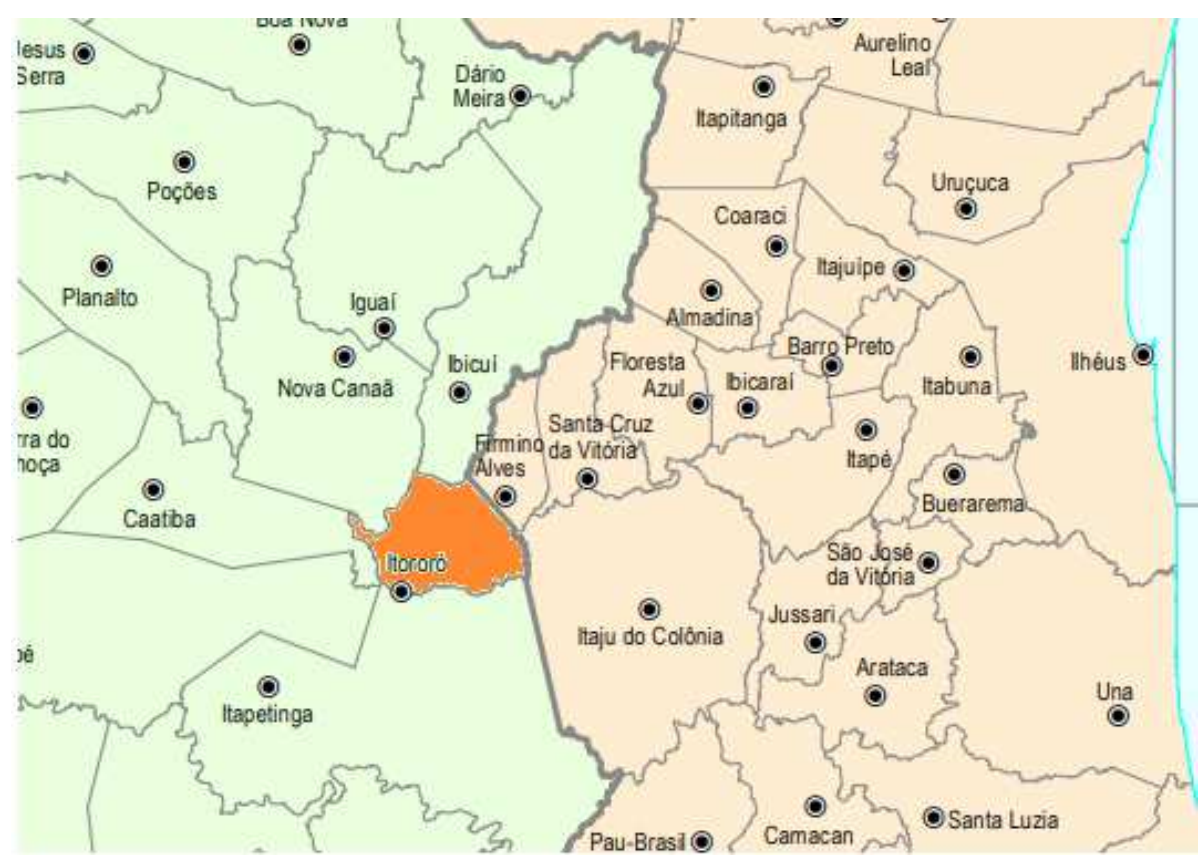

Fonte: Instituto Brasileiro de Geografia e Estatística (2016)

Território é definido "[...] como espaço delimitado pelas relações de poder, a identidade territorial é a expressão cultural e do estoque de fatores endógenos que identificam esse território" (MAIORKI; DALLABRIDA, 2015, p. 17). 
O município de Itororó foi constituído por três distritos: Itororó, Itati e Rio do Meio, divisão territorial definida em 2007, que está em vigor até o momento, e congrega a diversidade cultural dessa região (INSTITUTO BRASILEIRO DE GEOGRAFIA E ESTATÍSTICA, 2016) .

\subsection{Considerações sobre o Potencial para IG Itororó, Produto Carne de Sol}

A principal atividade econômica de uma região, cuja identidade esteja vinculada a uma Indicação geográfica e que gera renda ao município, é o turismo (EMPRESA BRASILEIRA DE PESQUISA AGROPECUÁRIA, 2017).

O Festival da Carne de Sol de Itororó, também conhecido na região e em toda a Bahia, como Festisol, encontra-se na sua $30^{\circ}$ edição, é o ponto alto do turismo do município, pois já está previsto no calendário de eventos da população regional, sendo importante para a cultura popular.

O Festisol ocorre no mesmo período da festa de São João, segundo Santana (2006, p. 17):

Ocorrem na região encontros festivos e turísticos similares em cidades próximas de Itororó (Itapetinga e Ibicuí), porém, o FESTSOL destaca-se pelos aspectos econômicos, representa também alternativa social e cultural para a comunidade e, por esta razão pode ser analisado como vetor do desenvolvimento por intermédio das atividades culturais.

Essa tradição começou em 1977 com a chegada da família do senhor Joaquim Prates à cidade. Essa família tornou-se, posteriormente, pioneira na preparação da carne de sol, já que na época essa era a cultura local, com o passar do tempo, essa tradição possibilitou que o munícipio atingisse notoriedade nacional e até mesmo internacional (CÂMARA MUNICIPAL DE ITORORÓ, 2014).

No mundo atual, caracterizado pelas rápidas mudanças culturais, "O duplo requisito de qualidade e identidade expresso [...] assumiu particular importância" (MUCHNIK; BIÉNABE; CERDAN, 2005, p. 2, tradução nossa). Nesse contexto, o alimento "[...] adquire um papel essencial na busca de cada indivíduo pela identidade pessoal, na 'individuação' das pessoas e das sociedades" (MUCHNIK; BIÉNABE; CERDAN, 2005, p. 2, tradução nossa).

A notoriedade referente ao preparo da carne de sol, atribuída à família do senhor Joaquim Prates, fez com que o município de Itororó ficasse identificado como referência para obtenção de um determinado produto. Nesse sentido, Rezende et al. (2015) afirmam que a fama das cidades ou das regiões são estabelecidas em função de produtos e serviços que possuem qualidade $e$ tradição pela sua origem, podendo ser utilizada para a devida proteção.

A carne de sol de Itororó é um produto selecionado, com origem no abate de novilho precoce, os cortes especiais são separados e preparados de acordo com os conhecimentos dos produtores da região, o que confere ao produto características especiais, como sabor diferenciado, bom aspecto visual e maciez. Como se trata de produto alimentício, de origem animal, obrigatoriamente são inspecionados pelos órgãos responsáveis, seguindo a norma interna DAS n. 4 do Ministério da Agricultura, Pecuária e Abastecimento. De acordo com a Secretaria de Defesa Agropecuária, é preciso 
Aprovar o programa de avaliação de conformidade de padrões físico-químicos e microbiológicos de produtos de origem animal comestíveis e água de abastecimento, registrados e relacionados no Serviço de Inspeção Federal e de produtos de origem animal, comestíveis. (BRASIL, 2013, art. 1)

Guimarães e Silva (2014) avaliam que a "carne de sol de Piquî" da região do Seridó paraibano e do norte rio-grandense possui potenciais elegíveis para um processo de avaliação, melhoria de qualidade e posterior certificação, estando em nível de qualidade comparável ao da carne de sol de Itororó.

\subsection{Análise do Potencial do Caso Itororó à Luz da LPI}

A LPI apresenta no seu Título IV, Das Indicações Geográficas, os artigos que definem os conceitos relacionados aos tipos de IG e os requisitos mínimos para concessão e situações de adequação de uso de IG e da marca.

No Quadro 1 são apresentados os elementos da lei aplicáveis à potencial IG Itororó, referente ao produto carne de sol. Para atendimento do artigo 176 da referida lei, o produto objeto da solicitação da IG deve ter indicação de procedência ou indicação de origem, então, a carne de sol de Itororó possui uma história criada em 1977 e essa história não se perdeu ao longo do tempo, muito pelo contrário. O modo de preparo do produto fez com que os habitantes da região desenvolvessem o interesse pela atividade de elaboração do produto, por isso, se transformou em uma atividade de produção local. De acordo com Valente, Perez e Fernandes (2013), a tradição produtiva regional "saber fazer", em pesquisa realizada, obteve a maior parte dos votos coletados.

Quadro 1 - Elementos da lei que se aplicam a potencial IG Itororó, referente ao produto carne de sol

\begin{tabular}{|c|c|c|}
\hline $\begin{array}{c}\text { ARTIGOS LEI N. } \\
\mathbf{9 . 2 7 9 / 9 6}\end{array}$ & ElEMENTo DA LEI & $\begin{array}{c}\text { EM RELAção À REFE- } \\
\text { RIDA IG }\end{array}$ \\
\hline 176 & Indicação de procedência (IP) ou (DO) Denominação de origem & Aplicável \\
\hline 177 & Nome da cidade como indicação de procedência (IP) & Aplicável \\
\hline 178 & Qualidade ou característica exclusiva ao meio geográfico & $\begin{array}{c}\text { Aplicável (fatores } \\
\text { humanos) }\end{array}$ \\
\hline 179 & $\begin{array}{c}\text { Proteção para a representação gráfica ou } \\
\text { figurativa e a representação geográfica }\end{array}$ & Aplicável \\
\hline 180 & Nome do produto ou serviço se tornou comum. & Não Aplicável \\
\hline 181 & Nome geográfico que não constitua IP nem DO. & Não Aplicável \\
\hline 182 & Uso restrito da indicação geográfica & Aplicável \\
\hline
\end{tabular}

Fonte: Elaborado pelos autores deste artigo

Referente ao artigo 177 da lei que é aplicável (IP), como mostra o Quadro 1, o nome da cidade pode ser considerado uma indicação de procedência, uma vez que o nome da região está diretamente associado à produção e à comercialização do produto. Brandão et al. (2012) consideram que a indicação de origem geográfica pode ser admitida como um atributo diferenciador, fruto das ações locais por causa da criação de marcas geográficas, com o objetivo 
de valorizar o uso e os costumes locais. Por outro lado, Fonte e Dallabrida (2016) acreditam que se trata de uma distinção atribuída aos produtos, que se destacam pela sua especificidade territorial, associada à notoriedade.

Analisando o artigo 178 da Lei n. 9.279/96 (Quadro 1), evidencia-se que o produto ou serviço possui qualidade ou características atribuídas exclusivamente ao meio geográfico, ou seja, considera-se que as características do produto/serviço sejam essencialmente derivadas de fatores naturais e humanos. A princípio, podem ser atribuídas à carne do sol de Itororó características exclusivas relacionadas a fatores humanos, na medida em que são decorrentes no modo de fazer próprio de um grupo ou comunidade. Neiva, Sereno e Fioravanti (2011) ponderam que as indicações geográficas agregam valor ao produto, pois ao produto são incorporadas a história, as questões culturais, a identidade local e o saber fazer; por outro lado, Nascimento e Dallabrida (2012) afirmam que a relação existente entre indicação geográfica e desenvolvimento territorial é muito forte, pois gera a valorização da região por meio de seus habitantes que passam a reviver as tradições e a cultura.

Considerando o artigo 179, como mostra o Quadro 1, a proteção se estende à representação gráfica ou figurativa da indicação geográfica. Isso quer dizer que as representações gráficas ou figurativas, relacionadas à referida IG, também estarão protegidas, inclusive essa condição se assemelha ao registro de marcas caso já exista marca semelhante, pois a pretendente não poderá ser registrada. Segundo a Lei n. 9.279, "São suscetíveis de registro como marca os sinais distintivos visualmente perceptíveis, não compreendidos nas proibições legais" (BRASIL, 1996, art. 122).

Tendo em vista o artigo 180 da Lei n. 9.279, "Quando o nome geográfico se houver tornado de uso comum, designando produto ou serviço, não será considerado indicação geográfica" (BRASIL, 1996, art. 180). Conforme mostram os dados do Quadro 1, entende-se que o nome geográfico referente à carne de sol de Itororó, BA, não se constitui em caso de uso comum. Segundo o Instituto Nacional de Propriedade Industrial (2018b , p. 45), "Uma vez que o nome geográfico se torne genérico - percebido pelo público como tipo de produto ou de serviço não poderá ser protegido como indicação geográfica, pois perdeu a evocação à sua região de origem".

Analisando o artigo 181, apresentado no Quadro 1, percebe-se que o nome geográfico que não constitui indicação de procedência ou denominação de origem poderá servir de elemento da marca para produto ou serviço; mas esse artigo tem como premissa básica não induzir falsa procedência, essa precaução, entre outros objetivos, é para evitar confusão na cabeça do consumidor final.

Com base no artigo 182 da Lei n. 9.279/96, apresentado no Quadro 1, nota-se que o uso da indicação geográfica é restrito aos produtores e aos prestadores de serviço estabelecidos no local, pois normalmente os produtores ou prestadores de serviços são pertencentes a grupos e associações que já existiam e que, por sua vez deram origem à IG.

A Indicação Geográfica traz como benefícios a organização coletiva dos produtores, o estímulo à economia local e a ampliação do nome dos produtos na região, com impactos na competitividade e no aumento do potencial para a atividade turística relacionada ao produto. Cada IG está vinculada a uma associação de produtores que deve atuar na gestão dessa IG, incluindo o controle, a proteção e a sua promoção (EMPRESA BRASILEIRA DE PESQUISA AGROPECUÁRIA, 2017). 


\subsection{Análise a Partir da Existência da IG}

Além da diferenciação e da notoriedade do produto, existem outros ganhos que podem ser alcançados com a concessão da IG, tomando como alguns casos de sucesso o vinho de uva Gothe da região de Urussanga. Essa região é formada pelos munícipios de Pedras Grandes, Urusanga, Treze de Maio, Cocal do Sul e Orleans e recebeu em novembro de 2011 o registro de IP, sendo a primeira indicação geográfica de Santa Catarina. Schneider, Zilli e Vieras (2017) revelam em pesquisa que, a partir de 2011, o preço por quilo da uva aumentou em pelo menos $20 \%$ em quatro dos cinco municípios que fazem parte da referida região, o preço da produção e o rendimento médio de uvas produzidas por hectare, praticamente, cresceram em todos os municípios e o valor da produção aumentou em quatro municípios aproximadamente $20 \%$. Em outra análise, no ano de 2002, o Vale dos Vinhedos teve sua IG concedida na modalidade Indicação de Procedência. E, segundo a Empresa Brasileira de Pesquisa Agropecuária (2014), a fim de contribuir com o sucesso da referida IG e de outras demandas que foram geradas por associações de produtores da região, a empresa especializada criou uma metodologia de avaliação de impactos econômicos, sociais e ambientais para indicações geográficas, dividida em seis fases:
a) delimitação do objeto de avaliação;
b) verificação das dimensões de impacto e identificação de atores relevantes;
c) construção das estruturas de impactos;
d)definição e preparação dos instrumentos de medida de campo;
e) obtenção das medidas de campo; e
f) avaliação dos impactos.

\section{Considerações Finais}

São diversos os fatores que contribuem para se obter uma IG no Brasil, entre eles considera-se a diversidade cultural, o território e sua identidade e as diversas peculiaridades de natureza ambiental e humana.

A carne de sol de Itororó está relacionada com o "saber fazer" de uma comunidade tradicional, existe uma região identificada que se relaciona ao produto localizada no município de Itororó. Portanto, a carne de sol de Itororó possui grande potencial em receber uma Indicação Geográfica na modalidade Indicação de Procedência (IP), uma vez que está ligada a fatores humanos e não a fatores ambientais.

A carne do sol de Itororó está relacionada com o saber fazer de uma comunidade tradicional, existe uma região identificada que se refere ao produto, localizada no município de Itororó. Portanto, a carne do sol de Itororó possui grande potencial em receber uma Indicação Geográfica na modalidade Indicação de Procedência (IP). Todavia, em estudos futuros poderiam ser identificados fatores humanos relevantes, os quais qualificam e diferenciam o produto, dando possibilidade de se analisar a viabilidade do potencial para a Indicação de Denominação (DO). 
Existem na região atores interessados em tornar a IG realidade, como associações e, principalmente, as empresas de donos de açougue e a prefeitura municipal, por meio da Secretaria Municipal de Turismo.

\section{Referências}

BRANDÃO, A. C. et al. Confiança e agregação de valor em carnes com indicação geográfica. Arq.

Bras. Med. Vet. Zotec., [S.l.], v. 64, n. 2, p. 458-464, 2012.

BRASIL. Lei n. 9.279, de 14 de maio de 1996. Lei de Propriedade Intelectual. Regular direitos e obrigações relativos à propriedade industrial. Disponível em: <http://www.planalto.gov.br/ccivil_03/ Leis/19279.htm > . Acesso em: 18 maio 2018.

BRASIL. Ministério da Agricultura, Pecuária e Abastecimento (MAPA). Norma Interna DAS n. 04, de 16 de dezembro de 2013. MAPA, Secretaria de Defesa Agropecuária, 2013.

CÂMARA MUNICIPAL DE ITORORÓ. [2014]. Disponível em: < http://www.camara.itororo.ba.io.org. br/historia > . Acesso em: 20 maio 2018.

COSTA, E. R. C. As Indicações Geográficas como Elementos Fortalecedores para a Atividade Turística. Turismo: Estudos \& Práticas (RTEP/UERN), Mossoró, RN, v. 3, n. 1, p. 25-50. 2014. Disponível em: < http://periodicos.uern.br/index.php/turismo/article/download/1073/588> . Acesso em: 6 jul. 2018.

EMPRESA BRASILEIRA DE PESQUISA AGROPECUÁRIA (EMBRAPA). Metodologia de avaliação de impactos econômicos, sociais e ambientais para indicações geográficas. 2014. Disponível em: <http://www.embrapa.br/uva-e-vinho>. Acesso em: $1^{\circ}$ set. 2018.

FONTE, L. C. C.; DALLABRIDA, R. V. Governança territorial em experiências de indicação geográfica: Análises e prospecções. DRd - Desenvolvimento Regional em debate, [S.l.], v. 6, n. 2, ed. esp., p. 228-246, 2016. Disponível em: < http://www.periodicos.unc.br/index.php/drd/issue/ view/41>. Acesso em: 22 maio 2018.

GUIMARÃES FILHO, E.; SILVA, G. C. P. Indicação geográfica, uma certificação estratégica para os produtos de origem animal da agricultura familiar do semiárido. Rev. Econ. NE, Fortaleza, v. 45, p. 114-123, 2014. Disponível em: < http://edi.bnb.gov.br/content/aplicacao/publicacoes/ren-numeros publicados/docs/ren_2014_10_clovis_v2.pdf > . Acesso em: 22 maio 2018.

INSTITUTO BRASILEIRO DE GEOGRAFIA E ESTATÍSTICA (IBGE). Biblioteca IBGE. [2016]. Disponível em: <https://biblioteca.ibge.gov.br/visualizacao/dtbs/bahia/itororo.pdf > . Acesso em: 22 maio 2018.

INSTITUTO NACIONAL DE PROPRIEDADE INDUSTRIAL (INPI). Instrução Normativa n. 25/2013 - Estabelece as condições para o registro das indicações geográficas. [2013]. Disponível em: <www.inpi.gov.br> . Acesso em: 20 maio 2018.

INSTITUTO NACIONAL DE PROPRIEDADE INDUSTRIAL (INPI). Indicadores de Propriedade Industrial 2018: o uso do sistema de propriedade industrial no Brasil. Diretoria Executiva. Assessoria de Assuntos Econômicos. 2018a. Disponível em: <http://www.inpi.gov.br/sobre/ estatisticas/arquivos/pagina-inicial/indicadores-de-propriedade-industrial-2018_versao_portal.pdf $>$. Acesso em: 5 jun. 2018. 
INSTITUTO NACIONAL DE PROPRIEDADE INDUSTRIAL. (INPI). [2018b]. Disponível em: < http:// www.inpi.gov.br>. Acesso em: 5 jul. 2018.

MUCHNIK, J.; BIÉNABE, E.; CERDAN, C. Food identity/food quality: insights from the "coalho" cheese in the Northeast of Brazil. Anthropology of food, Local Foods, v. 4, 2005. Disponível em: $<$ https://journals.openedition.org/aof/110>. Acesso em: 7 jul. 2018.

MAIORKI, G. J.; DALLABRIDA, V. R. A indicação geográfica de produtos: um estudo sobre sua contribuição econômica no desenvolvimento territorial. Interações, [S.l.], v. 16, n. 1, p. 13-25, 2015. Disponível em: <http://www.scielo.br/pdf/inter/v16n1/1518-7012-inter-16-01-0013.pdf>. Acesso em: 6 jul. 2018.

NASCIMENTO, N. J.; DALLABRIDA, R. V. Direito e desenvolvimento territorial: as questões legais que envolvem a indicação geográfica de produtos e serviços no Brasil e no exterior. 2012. Disponível em: < https://seer.faccat.br/index.php/coloquio/article/download/388/326>. Acesso em: 20 maio 2018.

NEIVA, A. C. G. R.; SERENO, J. R. B.; FIORAVANTI, M. C. S. Indicação geográfica na conservação e agregação de valor ao gado curraleiro da comunidade Kalunga. Arq. Bras. Med., [S.l.], Vet. Zotec., 2011.

REZENDE, A. A. et al. Contribuições para indicação geográfica (IG): considerações sobre Buerarema - Ba como um potencial IG para farinha de mandioca. Cad. Prospec., [S.I.], v. 8, n. 4, p. 791-800, 2015.

RUSSO, S. L. et al. organizadores. Propriedade intelectual, tecnologias e sociedade. São Cristóvão: Editora UFS, 2016. 332 p.

SANTANA, F. A. Turismo como vetor de desenvolvimento local: o caso do Festival de Carne do Sol - FESTSOL. Itororó: Bahia. 2006.

SCHNEIDER, M.; ZILLI, J.; VIERAS, A. os impactos da indicação de procedência no desenvolvimento econômico na produção de uva, nos municípios dos vales da uva goethe - SC.

Cad. Prospec., Salvador, v. 10, n. 2, p. 327-340, abr.jun. 2017.

TRIPS. Trade-Related Aspects of Intellectual Property Rights (unamended version). Morocco, 1994. Disponível em: <https://www.wto.org/english/docs_e/legal_e/27-trips_01_e.htm>. Acesso em: 7 jul. 2018.

VALENTE, R. E. M. et al. Indicação geográfica de alimentos e bebidas no Brasil e na União Europeia. Ciência Rural, [S.l.], v. 42, n. 3, p. 551-558, 2012. Disponível em: < http://www.scielo.br/ pdf/cr/v42n3/a7712cr5407.pdf>. Acesso em: 20 maio 2018.

VALENTE, M. E.; PEREZ, R.; FERNANDES, R. L. O processo de reconhecimento das indicações geográficas de alimentos e bebidas brasileiras: regulamento de uso, delimitação da área e diferenciação do produto. Ciência Rural, v.43, n.7, p.1330-1336, 2013. Disponível em: < http:// www.scielo.br/pdf/cr/2013nahead/a18113cr2012-0405.pdf> . Acesso em: 20 maio 2018.

ZUIN, S. F.; ZUIN, B. P. Produção de alimentos tradicionais - Contribuindo para o desenvolvimento local/regional e dos pequenos produtores rurais. Taubaté, SP, Brasil. Revista Brasileira de Gestão e Desenvolvimento Regional, [S.l.], v. 4, n. 1, p. 109-127, 2008. Disponível em: <http://www. rbgdr.net/012008/artigo5.pdf> . Acesso em: 20 maio 2018. 


\section{Sobre os autores}

\section{Joelito Cruz Santos}

E-mail: joelitocs70@gmail.com

Pós-graduado em Gerenciamento de Projetos. Mestrando em Propriedade Intelectual e Transferência de Tecnologia, Professor do IFBA.

Endereço profissional: Instituto Federal de Educação, Ciência e Tecnologia da Bahia, Instituto Federal de Educação, Ciência e Tecnologia da Bahia, Campus Simões Filho. Via Universitária, s/n, Pitanguinha, Simões Filho, BA. CEP: 43700-000.

\section{Wagna Piler Carvalho dos Santos}

E-mail:wagna.ifba@gmail.com

Doutora em Química pela Universidade Federal da Bahia-UFBA (2007). Mestre em Química pela UFBA (2003). Endereço profissional: Instituto Federal de Educação, Ciência e Tecnologia da Bahia, Instituto Federal de Educação, Ciência e Tecnologia da Bahia, Campus Salvador. Rua Emídio dos Santos, s/n, Barbalho, Salvador, BA. CEP: 40110-150. 